\title{
Los fantasmas del poder: coca, guerrillas y elecciones en Perú
}

Ricardo Melgar

1

1

3
LA PROFILAXIS ELECTORAL DE LA DEA (DRUG ENFORCEMENT ADMINISTRATION)

$\mathrm{L}$ os países delárea andina atraviesan en la actual coyuntura una difícil situación económica y política que los hace desempeñar, después de la región centroamericana-Panamá incluido-, el segundo teatro de desarrollodelo que eufemísticamente los estrategas del Pentágono han denominado "conflictos de baja intensidad" (CBI). Crisis económica, inestabilidad política, insurgencia armada, narcotráfico y creciente injerencia norteamericana en los asuntos internos de estos países, signan más allá de sus matices y diversos grados de desarrollo, los principales rasgos del momento histórico que les toca vivir.
Ya desde la reunión de los ejércitos americanos en Mar del Plata (del 16 al 20 de noviembre de 1988), Frederick F. Woerner, en ese entonces jefe del Comando Sur del ejército norteamericano, había señaladola existencia de una diversidad de situaciones nacionales en América Latina, que debían considerarse como "conflictos de baja intensidad". La misma postura fue reafirmada poco después por este general estadunidense, involucrando el área andina al lado de la centroamericana. ${ }^{1}$

En este contexto problemático debemos situar el análisis del caso peruano en vísperas del proceso electoral y de relevo

${ }^{1}$ Prensa Latina, Montevideo, 20 de diciembre de 1988. 
gubernamental que cumplirá cuando se haga la transmisión del mando presidencial el 28 de julio de este año. Durante los comicios del 8 de abril se elegirán, además del nuevo presidente de la república, a dos vicepresidentes, 60 senadores, 180 diputados y un número indeterminado de autoridades regionales. Por ello empezaremos por rastrear las variables no económicas que por su articulación externa condicionan el actual proceso político-electoral de este país sudamericano: la lucha contra el narcotráfico y la insurgencia guerrillera asociada a la crecienteinjerencia estadunidense. Los otros dos condicionantes económicos, la deuda externa y la composición de las divisas los veremos más adelante, tanto por sus incidencias electorales como por su acción condicionante sobre las tendencias coyunturales de alcance poselectoral. Es conocida la penosa carga de una deuda externa cercana a los 19000 millones de dólares para un país con aguda recesión económica, que fue declarado inelegible por el FMI desde agosto de 1986. Esta situación se revela más crítica al analizar la balanza real del comercio exterior, en la que el rubro no declarado de ingresos procedentes del narcotráfico, estimados entre 1500 y 2000 millones de dólares, opera como un soporte necesario de la captación de divisas, frente a los 2700 millones de dólares procedentes de sus exportaciones tradicionales y complementarias. $^{2}$

El relevo del general Frederick $F$. Woerner por el general Maxwell Thurman en la jefatura del Comando Sur de Estados Unidos el 30 de septiembre de 1989, no ha significado un cambio en las

2 José María Salcedo, "La coca en cifras", Quebacer, Lima, núm. 59, junio-julio de 1989, p. 42.

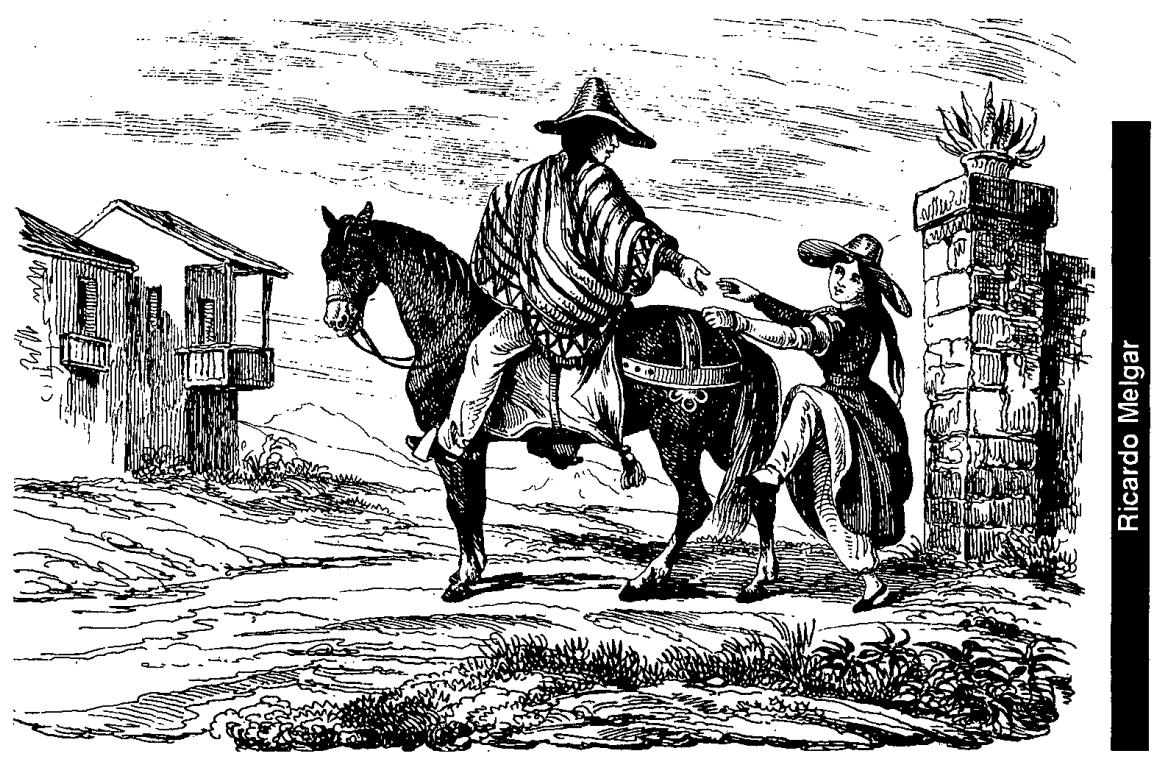


estimaciones del Pentágono, aunque sí en su metodología y objetivos en el corto y mediano plazo para el área andina, y particularmente para el Perú. Las más recientes experiencias intervencionistas en Panamá y Colombia parecen refrendarla. Dos dias antes de este cambio de mando, el Programa de Estudios de Seguridad Internacional de la Universidad de Georgetown hizo circular en las altas esferas gubernamentales de Washington un informe donde da prioridad a las tareas de inteligencia militar en el área, en términos análogos a los acordados en la Conferencia de Inteligencia Militar de Mar del Plata, a iniciativa de Woerner, sobrela subversión en el continente. En ese caso la clave a seguir consistía en la modernización de los servicios de inteligencia de cada país y en el libramiento de acciones combinadas contra las guerrillas y el narcotráfico. ${ }^{3}$

La nueva orientación que propone el informe de la Universidad de Georgetown, responde a una valoración más acorde a las exigencias de los CBI en la nueva coyuntura internacional de distensión este-oeste, con el fin de proveer un apoyo adecuado para el tratamiento de los mismos. Elbalance de la década de los años ochenta para Estados Unidos, según este informe, "es una larga lista de fracasos militares y políticos". Por ello, uno de estos expertos en CBI, Neil Livingstone, considera que el Pentágono debe articularsu red de inteligencia electrónica con aquella otra "inteligencia adecuada", proporcionada a veces por "personas muy desagradables" que sirvan de plataforma para la construcción y acción efectiva de fuerzas especiales en CBI. ${ }^{4}$ ¿Serán

${ }^{3}$ Alan Riding, The New York Times, 6 de octubre de 1988. 1989. algunos narcos tolerados, los ejemplos vivos de esta propuesta?

En este contexto no será difícil descubrir que el perfil de la DEA se asemeja al de una fuerza operativa especial para CBI en algunos países del continente. La década de los años noventa, nos dará más luces sobre los otros rostros de las fuerzas interventoras norteamericanas, así como de las nuevas funciones del Comando Sur. Según el Centro de Información Militar de Washington, el Comando Conjunto de Operaciones Especiales del Pentágono incluye a efectivos del VII Batallón del Grupo de Fuerzas Especiales con base en Fort Bragg y un batallón en Fort Davis, Panamá, cuya principal responsabilidad son las actividades en América Latina. ${ }^{5}$ Durante el periodo de mando del general Woerner, efectivos de estas unidades cumplieron funciones de reconocimiento y entrenamiento en Perú, Bolivia, Colombia y Ecuador. A fines de 1989, el general Thurman tenía destacados a 227 oficiales norteamericanos en Colombia, Perú y Bolivia cumpliendo funciones diversas de avanzada, deloqueacertadamente Saxe-Fernández ha denominado "una ocupación silenciosa que ocurre paralelamente con procesos de integración silenciosa". 6

En el caso peruano interesa saber si la DEA, y en general la política norteamericana, afecta de manera directa el curso del actual proceso electoral en el marco de una guerra interna en desarrollo.

Es de conocimiento internacional que las dificultadesy diferencias habidas entre el régimen aprista de Alan García y el gobierno republicano de Ronald Reagan no cancelaron las tareas y programas de

${ }^{5}$ John Saxe-Fernández, "Iberoamérica ante EU. Riesgos estratégicos", Excélsior, México, 20 de febrero de 1990 .

${ }^{6} \mathrm{Ibid}$.
1 
cooperación antisubversiva, canalizadas principalmente mediante la campaña antidrogas de la DEA en la región amazónica, en la que se ubican las retaguardias de las dos principales fuerzas insurgentes: el Movimiento Revolucionario Túpac Amaru (MRTA) y el Partido Comunista del Perú (Sendero Luminoso: SL), así como la base principal de la economía cocalera, calculada entre 200000 y 300000 hectáreas de plantaciones de coca, ubicadas en su mayor parte a lo largo de los 7800 kilómetros cuadrados del valle de Huallaga en el corazón de la Amazonia peruana.

Si nos atenemos a los limitados objetivos señalados por el plan Bennet de abatir gradualmente el consumo de drogas en Estados Unidos -en el cual la cocaína y sus derivados ocupa un lugar secundario frente a la heroína y otras drogas, pues se registran 3000000 de adictos de un total estimado de $14.5 \mathrm{mi}$ llones, según datos de 1988 que al parecer no consideran a los consumidores ocasionales ${ }^{7}$ no podremos entender ni el cronograma ni la magnitud de la escalada intervencionista estadunidense en el área andina. Tampoco podemos explicarla a partir delos limitados y controvertidos acuerdos de Cartagena de febrero de 1990, suscritos entre los presidentes George Bush y sus homólogos de Colombia, Perú y Bolivia. La lógica intervencionista bajo la bandera "legitimadora" de lucha contra las drogas y el narcotráfico, revela más bien los agudos niveles de polarización política y explosividad social de los países andinos bajo los marcos omnicomprensivos de la ideología de los CBI.

\footnotetext{
7 Corinne Schmidt, "La coca: entre las armas y el desarrollo", Quebacer, Lima, núm. 61, octubrenoviembre de 1988 , pp. $80-86$.
}

Esta lógica real explica también ciertos antecedentes. Por ejemplo, que la presencia de militares norteamericanos en Perú fuese justificada a posterioni mediante el acuerdo antinarcóticos Wagner-Watson del 20 de mayo de 1987 y que fuera objetado por la bancada parlamentaria de izquierda por tener alcances lesivos a la soberanía nacional. ${ }^{8}$ Fue por ello que la orientación de la primera campaña profiláctica de la DEA, denominada Cóndor VI, tuviese como principal antagonista a las fuerzas guerrilleras. ${ }^{9}$

Efectivos de la DEAy del Comando Sur han ajustado sus tareas y programas hacia objetivos principalmente contrainsurgentes. Sus dos bases de operación las conforman el cuartel de Mazamari y el de Santa Lucía. El primero, ubicado en la franja amazónica del departamento de Junín, a cargo de la policía nacional, para la formación de cuerpos especializados en lucha contrainsurgente, tanto en zona andina como en la amazónica. Esta función la venía desempeñando Mazamari, desde fines de los años sesenta, pero ahora, al haber modernizado y diversificado sus programas de adiestramiento gracias a la activa participación militar estadunidense, cumple una función de mayor envergadura al servicio de un programa de intervención neocolonial.

Por otro lado, la construcción de la base DEA de Santa Lucía, con un costo inicial de 3000000 de dólares, fue iniciada a principios de 1989 con proyección de control del valle del Huallaga y con capacidad para comenzar a albergar a 600 efectivos. La urgencia de su instalación y uso se ubica en el marco de las campañas

\footnotetext{
${ }^{8}$ Cambio, Lima, 22 de septiembre de 1987.

๑ Ibid, Lima, 26 de julio de 1987.
} 
contrainsurgentes previas a la contienda electoral. De febrero a agosto de 1989 , la DEAsuspendió las operaciones antidrogas con la finalidad de facilitar el trabajo de ocupación y consolidación militar de las unidades del ejército peruano en diversos puntos estratégicos del área. En ese lapso, las fuerzas armadas -sin el acoso de los programas antinarcóticos de la DEA - tratarían de restarle base social al MRTA y a SL en sus líneas de retaguardia y apoyo logístico (dólares, medicinas, armas, municiones, zonas de refugio y entrenamiento), intentando amagar así su capacidad de boicot del proceso electoral.

A partir del 8 de septiembre de 1989, la DEA desde la base de Santa Lucía y con el apoyo de 500 efectivos policiales entrenados en Mazamari, emprendió sus campañas punitivas en el valle del Huallaga, coordinando acciones con las fuerzas armadas peruanas en una compleja y no siempre armónica división del trabajo y de los espacios de combate y control político-militar.

Hacia el mes de diciembre de 1989, la DEA y sus efectivos policiales nativos declaraban haber bombardeado 25 laboratorios, destruido 30 pistas de aterrizaje y entrado en combate con unidades del MRTA y columnas senderistas. Funcionarios de la embajada estadunidense declararon haber aceptado el "argumento peruano" de que las guerrillas deben ser atacadas primero, abriendo áreas en las cuales la policía bajo conducción de la DEA pueda actuar contra los narcos. ${ }^{10}$

En el curso de esta accidentada campaña de fin de año, la DEA y la policía peruana resintieron no sólo el potencial de fuego del MRTA y de sL, sino también la

${ }^{10}$ Joseph B. Treaster, The New York Times, 10 de diciembre de 1989. respuesta de los narcos amazónicos que usaron armamento de fabricación israelí de alto poder, ${ }^{11}$ presumiblemente adquirido en Colombia por medio de las empresas Spearhead y Hod Hahanith.

Los exitosos operativos de la DEA mediante el uso de helicópteros artillados están respaldados por una impresionante cobertura tecnológica de la inteligencia militar estadunidense. El uso de satélites espías para cartografiar las selvas del Huallaga habla de una coordinación de mayor significación y envergadura. Efectivamente, participa en este proyecto de inteligencia militar la Agencia de Cartografía de la Defensa, el Instituto Geológico de Estados Unidos y algunos analistas privados especialmente contratados, como es el caso de Mark Labovitz, quien sostuvo que tenía la capacidad técnica de eliminar las imágenes de las áreas con densa vegetación para detectar laboratorios, zonas de cultivo y campamentos clandestinos. ${ }^{12}$

Esta coordinación de inteligencia responde al parecer a las directivas del Centro Antinarcóticos, recientemente creado a iniciativa de William $\mathrm{H}$. Webster, director de la CIA, con el fin de lograr una mayor y más efectiva tarea de centralización de las actividades de inteligencia, antiterrorismo y antinarcóticos de los diversos organismos estatales dependientes de los departamentos de Defensa, Estado y Justicia. ${ }^{13}$

La estrategia seguida por la DEA y las fuerzas armadas peruanas seguirá siendo beneficiada en términos crecientes por esta información. Al mismo tiempo se

${ }^{11}$ AFP (Associated France Press), Lima, 17 de diciembre de 1989.

${ }^{12}$ William J. Bread, The New York Times, 20 de octubre de 1989.

${ }^{13}$ Rolin Wright y Ronald J. Ostrow, Los Angeles Times, 23 de agosto de 1989. 
deja abierta la cooperación con algunos grupos de narcotraficantes y comités campesinos cultivadores de coca, con el fin de enfrentar nuevamente con éxito a las fuerzas guerrilleras. Los programas de sustitución de cultivos propuestos por los organismos de Naciones Unidas, será episódicos y marginales, como lo fueron en el denominado Triángulo de Oro en el sudeste asiático cuando trataron de eliminar los plantíos de amapola. La tendencia general de los operativos de la DEA se inclina a favor del herbicida Spike usado en Vietnam, y de manera selectiva en el valle del Huallaga, una escalada de bombardeos locales y el posible ensayo de formas novedosas de guerra biológica, como la sugerida recientemente después del acuerdo de Cartagena, de echar miles de huevecillos de una oruga que come hojas de coca, en la Amazonia.

El general del ejército peruano, Alberto Arciniega, jefe político y militar de la zona del Alto Huallaga y Tarapoto, es el artífice de una hábil estrategia antisubversiva en la región, pero que es motivo de discrepancias con la DEA. Arciniega ha frenado algunas campañas de la DEA por la represión indiscriminada que práctica contra guerrilleros, narcos y campesinos. Bajo la gestión del general Arciniega, los campesinos cultivadores de coca son tolerados y exonerados de los cupos sobre los precios de comercialización de las hojas de coca en el narcomercado por parte de los grupos insurgentes. Esta medida militar es coyunturalmente más atractiva para ciertos sectores del campesinado cocalero que las ofrecidas por las guerrillas; éstas se habían impuesto al poder despótico de los narcos en la región, al mismo tiempo que enfrentaron con éxito a la policía y a la DEA para favorecer la capacidad de venta de las hojas de coca por parte de los cultivadores. A cambio ganaban base social, consolidaban sus estructuras de poder local y lograban ciertos ingresos, alrededor de unos 30000000 de dólares anuales.

A los campesinos, el ejército les garantiza la venta de hojas de coca a algunos narcos considerados aliados tácticos por haber sufrido hostigamiento guerrillero, así como por su voluntad de cooperar en actividades de inteligencia, financiamiento y reorganización de las instancias de poder local. Liquidada la influencia guerrillera en las zonas de ocupación militar, afirma el general Arciniega, se procederá a poner en práctica la sustitución de cultivos; resulta obvio decir que alli donde se ha realizado ha resultado un verdadero fracaso por falta de infraestructura para su comercialización.

El objetivo militar de ganar a los campesinos cultivadores de coca en la región, que constituyen $80 \%$ de la población, se evidencia en las propias palabras del general Arciniega:

tenemos que tener en cuenta que el pro-
ductor de coca, el campesino cocalero, era
acosado por la policía y por cuanta fuerza
del orden existía, porque era considerado
un delincuente... Lo que hacemos, en-
tonces, es modificar esta situación para
evitar que el campesinado cocalero -la
base de que senutría Sendero para realizar
sus actividades- sea hostigado. Si se logra
que ellos, que son el pueblo, estén con
nosotros, entonces la guerra se encuentra
ganada.

Lo que no dice Arciniega es que el permiso de cultivo de coca, o más bien su tolerancia, no tiene ningún sentido si no va acompañado de la tolerancia para su comercialización por medio de los

${ }^{14}$ Raúl González, "Las armas de un general", entrevista con el general Alberto Arciniega, Quebacer, núm. 62, Lima, diciembre 1989-enero 1990, pp. 38-43. 
narcos. En este contexto los desajustes entre las tareas y objetivos de las fuerzas armadas, y los de la DEA y las fuerzas policiales, son más complicados de lo que parecen, conjugando diversos grados de cooperación y fricción.

La DEA y las fuerzas policiales han sido acusadas por el general Arciniega de vinculos con los narcos. Además, fuentes del ejército han indicado al ministro del Interior, Mantilla, al general Juan Zárate y a los jefes policiales Luque Freyre y Reyes Roca, que conforman el núcleo de dirección policial que coopera estrechamente con la DEA, de estar vinculados al cártel de Medellín y que sus operativos antinarcóticos sólo van dirigidos contra aquellos narcos nativos que tienen deseos y posibilidades de hacer autónoma su red de comercialización y sustraerse del tradicional control de las mafias colombianas en la actual coyuntura. ${ }^{15}$ Otras fuentes señalan que esta versión militar abona el hecho de que los canales del financiamiento que recibe Mantilla para sostener y ampliar las acciones terroristas de derecha del Comando Rodrigo Franco provienen de la conexión peruana del cártel de Medellín. A cambio, estos narcos demandan tolerancia selectiva en las campañas antinarcóticos, favorable, claro está, a sus intereses.

Este cronograma que cruza la lucha contrasubversiva con la desplegada contra el narcotráfico, espera alcanzar su primer clímax en el segundo trimestre del año. Así las fuerzas fiscalizadoras estadunidenses podrán seguir paso a paso el proceso electoral sin abandonar sus

15 The Peru Report, febrero de 1990, Lima. En visperas de la reunión antidrogas de Cartagena, la DEA logró que el gobierno peruano relevase del mandoal general Arciniega, colocandoen su lugar al general Luis Chacón. múltiplestareas. Porsu lado, la narcoburguesía se verá forzada a un realineamiento en la contienda electoral; en los últimos 25 años han ido ganando posiciones en las estructuras de poder local, regional y nacional. Conocidos son ciertos vínculos financieros aportados por connotados narcos peruanos a las campañas electorales de Acción Popular en 1980 y del APRA en 1985.

Son harto elocuentes los escándalos con implicaciones políticas que suscitaron César López Silva, dirigente nacional del APRA en la discutida libertad del oficial Carlos Lamberg -detenidó por tráfico ilícito de cocaína-y el diputado aprista Miguel Angel del Pomar por sus operaciones millonarias de lavado de dólares. También causó escozor el escándalo de Villa Coca en un barrio residencial de Lima, pues comprometió a connotados personajes.

La narcoburguesía se encuentra en una situación difícil. Acosada por la fuerza armada y la DEA, oscila entre romper el fuego contra las guerrillas, cooperar con las tareas de inteligencia y las campañas electorales de los candidatos más tolerantes, o cobijarse tras los campesinos cocaleros para indirectamente coexistir bajo el manto protector de las guerrillas e incluso beneficiarse con los desacuerdos diplomáticos del gobierno en turno en Washington por la ausencia de alternativas de desarrollo viables para la región amazónica. Pesan también en favor de la narcoburguesía, las presiones de los banqueros peruanos. Las utilidades extraordinarias obtenidas por concepto de lavado de dinero no son de poca monta; sabido es que involucran hasta la banca estatal, ávida de reposición de divisas.

Finalmente, el gobierno de Bush ofrece la ampliación de su ayuda militar de dos a 46000000 de dólares para oxigenar las tareas contrainsurgentes, fuera de un 


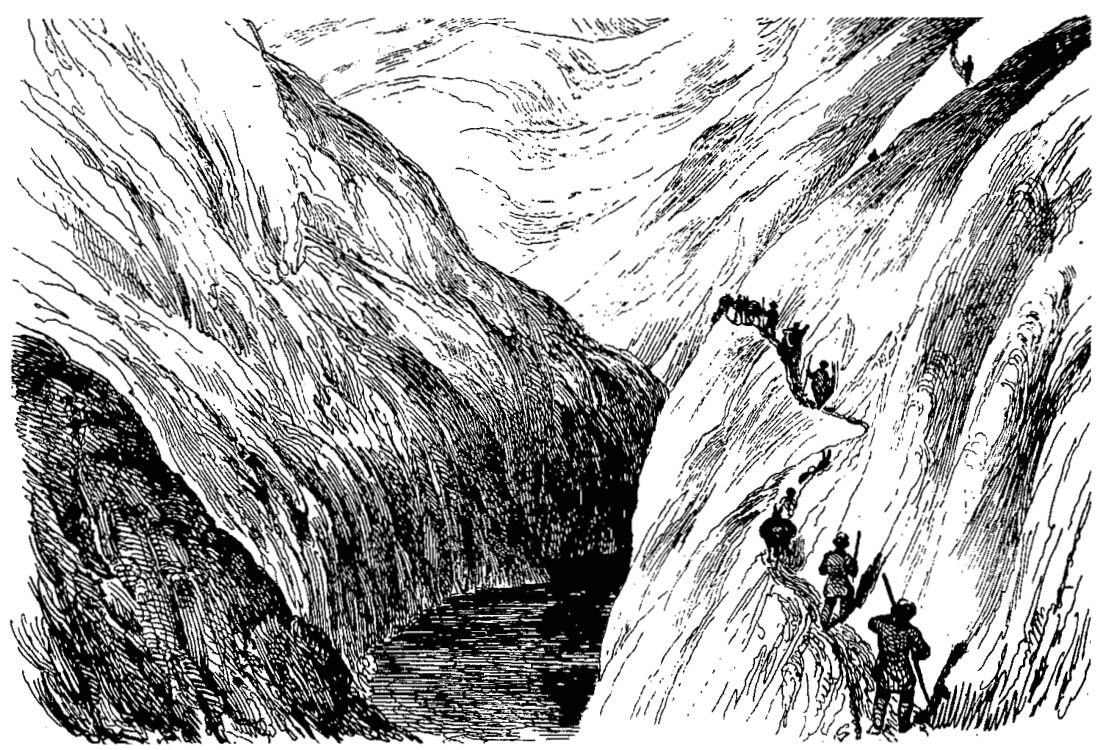

nuevo incremento a su programa antidrogas, y unos 34000000 de dólares para proyectos de desarrollo económico en las zonas de mayor tensión social. ${ }^{16} \mathrm{La}$ propuesta de ayuda militar para 1991 remitida por el presidente Bush al Congreso, de.la que se proveerá el nuevo gobierno peruano, implica un nuevo aumento al consignar 49000000 de dólares, así como otros reajustes en los rubros antidrogas y de desarrollo económico. ${ }^{17}$ En resumidas cuentas, la injerencia estadunidense seguirá un curso gradual y ascendente en el corto plazo, si nuevos elementos de la escena política no alteran significativamente la actual correlación de fuerzas y sus grados y modos de confrontación.

\footnotetext{
${ }^{16}$ AFP, Lima, 13 de febrero de 1990.

${ }^{17}$ AFP, Washington, 1 de febrero de 1990.
}

LOS JUEGOS DE PODER EN EL CONTEXTOELECTORAL

Diversos procesos electorales se vienen dando en América Latina bajo sus precarias estructuras políticas postoligárquicas, atravesadas tanto por la dinámica de sus fuerzas internas, como por las crecientes formas de presión internacional, particularmente de la política norteamericana para la región y de los grupos e instituciones financieras. Las banderas de la democracia (la "causa justa" en Panamá) y de la lucha contra el narcotráfico y el terrorismo en el área andina por razones de seguridad nacional, muestran las dos caras de la Casa Blanca con las que husmea y muerde nuestra soberanía continental.

En Perú las fuerzas de derecha han logrado aglutinarse en torno a un nuevo liderazgo carismático, el del conocido novelista Mario Vargas Llosa que en el 
corto plazo se convierte en la alternativa más viable de cambio gubernamental. El mosaico de las derechas en este país, geográficamente más amazónico que andino, asume como propias las mismas banderas imperiales para atacar los problemas nacionales, sin abandonar la esperanza de apelar a la ayuda militar norteamericana si continúan las fuerzas guerrilleras acrecentando su poderío político-militar. No es casual que Vargas Llosa deplorase acre y públicamente la iniciativa de Alan García de solicitar el retiro de Perú del Tratado Interamericano de Asistencia Recíproca (TIAR) y que ahora Paz Zamora reclama también para Bolivia. El "escribidor" esgrimió un solo argumento: en caso de necesitar ayuda militar externa para combatir el terrorismo, quedaríamos desamparados.

Esta declaración de Vargas Llosa es más propagandística y subjetiva que otra cosa. No obstante, el candidato sabe que declaraciones como ésta le ganan puntos a futuro en materia de negociaciones internacionales. En la realidad, las fuerzas intervencionistas norteamericanas no necesitan de tales llamadas de ayuda, salvo para justificar a posteriori sus acciones. Además, la DEA ya tendió su nropio puente.

Lo que sí destaca en la actual escena político-electoral de Perú es su entrelazamiento con los diversos aspectos de la guerra interna. Hay consenso en el hecho de que la batalla por las elecciones es parte importante de la lucha por la defensa del orden social y la reafirmación de sus instancias legales de poder, más aún, de la lucha en favor de las elecciones que es en cierto sentido una importante bandera contrainsurgente; planearla presupone un cronograma de acciones y medidas antisubversivas. Refiriéndose al proceso electoral en su conjunto, las elecciones municipales de noviembre y las gubernamentales del próximo abril, el comandante del ejército peruano, Artemio Palomino, manifestó: "estamos en una permanente guerra contra la subversión y no dejaremos ese accionar hasta derrotarla". ${ }^{18}$

Un conocedor de los CBI adjunto a la embajada norteamericana en la ciudad de Lima comentaba con agudeza, en vísperas de las elecciones municipales de noviembre, lo que parece ser consenso en las fuerzas armadas y en los partidos políticos contendientes, que Sendero no será capaz de subvertir ninguno de los dos procesos electorales. El analista pensaba más bien que la estrategia senderista "es reducir el número de candidatos y votantes para que la validez de las elecciones sea puesta en duda, y suscitar la posibilidad de que los militares retornen al poder", polarizando aún más a la sociedad peruana en beneficio de su proyecto de poder. ${ }^{19}$

Complejo proceso electoral en donde se cruza una abigarrada gama de contradicciones que van desde el antagonismo existente entre los partidos o instituciones que defienden el ya precario y vulnerable sistema electoral y las fuerzas que han optado por la lucha armada, hasta las disputas habidas entre los candidatos de cada lista para conquistar los votos preferenciales que otorga el sistema.

$\mathrm{El}$ régimen electoral vigente no es de los que podríamos denominar con exactitud democrático, corresponde a la variante DUSO (directo, universal, secreto y obligatorio), recomendada por la Liga de las Naciones durante el periodo de entreguerras para aquellos países que acababan de salir del paraguas colonial y

${ }^{18}$ AFP, Lima, 27 de octubre de 1988.

${ }^{19}$ Joseph B. Treaster, The New York Times, 25 de octubre de 1989.
1

2 
carecían de "experiencia y conciencia democráticas". La obligatoriedad del voto se justificaba en un país como Perú porque la población indígena, en su mayoría analfabeta, quedaba excluida del derecho al sufragio, y porque además pesaba sobre todo el sistema político, una significativa tradición de golpes y dictaduras militares. Se pensaba que presionando sobre la población votante se reforzaban los cimientos de una democracia por venir. La reforma constitucional de 1979 y la apertura de una nueva fase electoral, después de doce años de gobiernos militares, aun cuando ampliaron el universo de los ciudadanos con derecho a voto, consideraron oportuno mantenerla obligatoriedad del sufragio con la finalidad democrática de educar a las masas sin experiencia electoral por la vía del hecho. Iniciado el proceso de guerra interna, el abstencionismo considerado por definición ilegal y objeto de sanción pública y pecuniaria, se convirtió en un objetivo militar contrainsurgente.

En estas elecciones generales, bajo el contexto de una nueva fase de desarrollo de la guerra interna, cuentan mucho los mecanismos compulsivos, directos o indirectos, del sufragio. En el fondo, se trata de la propia legitimidad del sistema político; a pesar de la tradición coercitiva del empadronamiento y del sufragio electoral, se estima que poco más de 2000000 de potenciales electores, en su gran mayoría campesinos, han quedado fuera del registro electoral. Cada vez más se hacen frecuentes redadas masivas en las principales ciudades y se reportan un significativo número de indocumentados, es decir, sin libreta electoral o lo que es lo mismo sin cédula de identidad, migrantes rurales consideradossin más "sospechosos de terrorismo"; hostigados por las fuerzas del orden, tanto en el campo como en la ciudad, se convierten, a pesar suyo, en cada coyuntura electoral en virtual fuerza de impugnación.

Mientras que el Instituto Nacional de Estadística calcula en más de 12000000 la población mayor de 18 años obligada a participar en los comicios electorales, el Jurado Nacional de Elecciones registra a 9923062 empadronados, de los cuales estima que votarán alrededor de 7000000 . La formal exclusión de $21 \%$ de la población en edad de votar, no afectará la "legitimidad del proceso electoral", ya que para el Jurado Nacional de Elecciones, simple y llanamente no existen los que quedaron fuera del registro; en cambio, sí le preocupa el porcentaje estimado de abstencionismo.

La lucha más difícil es la que librarán las fuerzas contendientes por abatir el abstencionismo, así comolos votos blancos y viciados. Es la gran batalla institucional contra las opciones deslegitimadoras del MRTA (voto en blanco) y de Sendero Luminoso (boicot). En los recientes comicios municipales, el sistema logró pasar con relativo éxito la temible valla de las campañas insurgentes, aunque el Jurado Nacional de Elecciones no ha querido dar cifras de abstencionismo y de votos nulos y en blanco. ${ }^{20}$ No obstante, se filtró información regional acerca de reveses significativos. Así por ejemplo, en Huamanga, capital del convulsionado Ayacucho, a pesar del despliegue de fuerzas militares y policiales, el Jurado Nacional de Elecciones tuvo que reconocer que el abstencionismo ascendió a $72.80 \%$. Del esmirriado total de votos válidos, las dos terceras partes

${ }^{20}$ Caretas, núm. 1091, Lima, 15 de enero de 1990. El abstencionismo o los votos en blanco y viciados, abren un abanico de opciones políticas que rebasan las directivas del MRTA y de SL, aunque convergen en la deslegitimación del sistema electoral. 
correspondieron a votos blancos y viciados, por lo que el Jurado Nacional de Electores declaró nulo el proceso. ${ }^{21}$

En la ciudad de Lima, donde se encuentra más de un tercio del electorado nacional, los resultados de los comicios de noviembre no dejan de ser halagadores para el sistema, ya que la declinación del voto efectivo por algún candidato descendió de $85.29 \%$ en 1986, a $71.97 \%$, es decir, $13.32 \%$ capitalizado en términos de votos viciados, votos en blanco y abstencionistas registrados. ${ }^{22}$

Este universo electoral se complica aún más en el plano nacional si al abstencionismo no registrado le sumamos el efecto cualitativo de las acciones de aniquilamiento selectivo de los candidatos electos practicadas por Sendero Luminoso, pero también por el Comando Rodrigo Franco, brazo armado del Partido Aprista. De cualquier manera, la guerra interna en la coyuntura electoral todavía no inclina la balanza a favor de las fuerzas insurgentes impugnadoras del sistema político, aun cuando tengamos que reconocer que abarcan poco más de un tercio de la población nacional en edad de sufragio.

Las elecciones municipales de noviembre de 1989, parecen indicar quelos resultados electorales del 8 de abril de este año no variarán significativamente el panorama. Si el porcentaje efectivo de electores que respaldaron a algún candidato presidencial en los comicios de 1985, fue del orden de $77.28 \%$ y estimamos que se mantendrá la tasa decreciente de $13.22 \%$ de los comicios de noviembre pasado, se puede plantear la hipótesis de que el proyecto legitimador del sis-

\footnotetext{
${ }^{21}$ Ibid.

${ }^{22}$ Rafael Roncagliolo, "Elecciones en Lima: cifras testarudas", Quebacer, núm. 62, Lima, diciembre 1989-enero de 1990, p. 12-21.
}

tema electoral vigente será respaldado por una población de electores cercana a $64 \%$. Cabe la posibilidad de que la cifra sea aún menor. Consideremos quela tasa decreciente aplicada se tomó con base en datos de la capital, la cual tiende a desviarse por arriba de la media nacional en un $9.58 \%$ según datos del Jurado Nacional de Elecciones para el año de $1986 .{ }^{23}$

Definitivamente la correlación de fuerzas debe medirse más allá de estos ejercicios cuantificadores del sufragio y del abstencionismo. La voluntad política de las fuerzas electorales así como de las instituciones y fuerzas proelecciones (corporaciones empresariales, Iglesia, fuerzas armadas y centrales sindicales), indican que el sistema electoral, a pesar de sus debilidades crecientes, cuenta todavía con capacidad de maniobra suficiente para legitimar el relevo de mandos políticos en casi todo el territorio nacional, principalmente en las ciudades.

Sin embargo, en el seno del proceso electoral operan otros factores inherentes a la modalidad del sistema, que a pesar de ser promovidos o capitalizados por las diversas agrupaciones políticas que han registrado oficialmente a sus candidatos, pueden convertirse en elementos desestabilizadores de primer orden. Nos referimos en primer lugar al quórum exigido en la primera ronda electoral para obtener la banda presidencial. Con motivo de las pasadas elecciones generales (1985), Javier Alva Orlandini, el alicaído candidato del partido oficial Acción Popular, introdujo una cuña en el proceso al incorporar entre los votos válidos a los tradicionalmente considerados nulos (blancos y viciados). Pensaba así frenar la arrolladora campaña aprista

\footnotetext{
${ }^{23}$ Caretas, Lima, núm. 1091, 15 de enero de
} 1990 . 
que llevó a la presidencia de la república al hoy desgastado Alan García, al fijar el mínimo de $51 \%$ inalcanzable en la primera ronda. Acción Popular no contaba con que su candidato sólo alcanzaría un exiguo $7 \%$ dejándolo fuera de opción para la segunda y al parecer inevitable ronda electoral. Tampoco el partido oficial contaba con el hecho de que Alfonso Barrantes Lingán, el candidato de Izquierda Unida, renunciaría a participar en una segunda ronda en favor del en ese entonces flamante candidato aprista.

El gobierno de Alan García no se preocupó de derogar la ley 23903, misma que ahora utiliza para frenar las aspiraciones presidenciales del candidato del Frente Democrático (FREDEMO), Mario Vargas Llosa. Con la antigua ley de 1980, Mario Vargas LLosa necesitaría aproximadamente 3500000 votos a su favor; con la "ley Alva", que sigue vigente, requiere de aproximadamente 4250000 votos a su favor, cifra dificil de alcanzar si nos atenemos a los resultados que arrojan las encuestas de opinión. Por si fuera poco, el Partido.Acción Popular, demiurgo de tan maquiavélica ley, forma parte sustantiva de las fuerzas del FREDEMO. ${ }^{24}$

El ahora abatido Partido Aprista, aspira a concertar con las fuerzas de Izquierda Socialista e Izquierda Unida que comandan respectivamente Alfonso Barrantes y Henry Pease para mantenerse en el poder. Complicado proceso electoral en donde cuentan sin lugar a duda los movimientos subterráneos y las zancadillas políticas, más allá de la guerra de los spots televisivos, hoy en boga en un país en el que la técnica de las grandes concentraciones sociales ha pasado a tercer plano. Los crecientes riesgos de un atentado terrorista constituyen un poderoso factor disuasivo, pero

${ }^{24} \mathrm{Ibid}$, núm. 1092, 22 de enero de 1990. la campaña electoral no se ve disminuida por los espectaculares alcances propagandísticos que otorga la pantalla chica, sobre todo cuando se cuenta con recursos financieros.

La lucha por lograr la hegemonía en el Jurado Nacional de Elecciones va paralela con la disputa subterránea por las posiciones claves en el seno de las fuerzas armadas, garantes y custodios del proceso electoral. En el Jurado Nacional de Elecciones, por razones obvias, el Partido Aprista las tiene todas consigo. Los ruidosos reclamos de la oposición fredemista en torno a la inconstitucionalidad de la "ley Alva", el uso de sellos no indelebles, la recomposición arbitraria de las opciones electorales en las cédulas de sufragio y los sospechosos sistemas de conteo prolongado en las provincias, son harto conocidos. No basta pues tener voluntad y convicción de triunfo en la campaña electoral, hay también necesidad de fiscalizar los movimientos técnicos del proceso electoral.

Por si fuera poco, hay que librar la batalla en el propio seno de las fuerzas armadas. No es casual que algunas listas incluyan como candidatos a algunos militares de alto rango, especialistas en contrainsurgencia. El general Cisneros Vizquerra integra la planilla de Somos Libres, agrupación política que dirige el banquero Pardo Mesones. El Partido Aprista incluye al almirante Soria, ex ministro del interior del actual régimen, al teniente general de la fuerza aérea Hardy Montoya y al general del ejército, Parra.

Por su lado, el FREDEMO incorporó en su lista de candidatos al teniente general de la fuerza aérea Luis Arias Graziani, a los generales dél ejército, Sinesio Jarama y Antúnez de Mayelo así como al general de policía, Olivares. Además, los fredemistas cuentan con la Comisión de Apoyo 


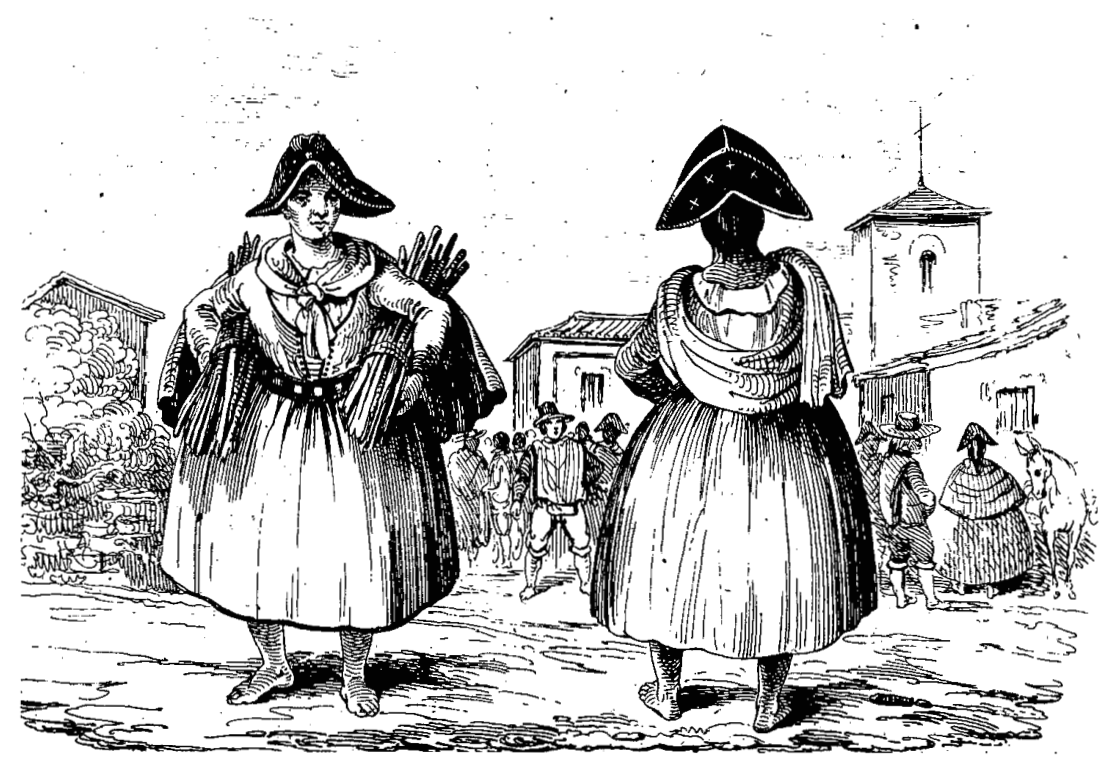

a la Lucha Antisubversiva en la que figuran, entre otros, el general Abram y el almirante Sánchez. ${ }^{25}$

Todos estos oficiales de alto rango involucrados en la campaña electoral se encuentran ya en situación de retiro, pero ello no implica su desvinculación castrense. Efectivamente, todos forman parte de la ADOGEN, una entidad consultiva del Comando Conjunto delas Fuerzas Armadas y del Ministerio de Defensa.

Pero la batalla por copar los mandos de las fuerzas armadas no se agota allí, la propicia el hecho de que el ejecutivo y el parlamento tengan injerencia directa en el orden de ascensos y mandos castrenses. Además se puso en el orden del día el asunto del veto o respaldo militar a la lista ganadora en los comicios de abril. En el nivel del Comando Conjunto, el comandante general del ejército, Jorge Zegarra

${ }^{25}$ Oiga, núm. 467, Lima, 29 de enero de 1990.
Delgado y el vicealmirante de la marina de guerra, Alfonso Paniza Zariquey, representan la tendencia filofredemista. La cuña aprista descansa esta vez en la persona del teniente general del aire, Germán Bucetich. El Partido Aprista fracasó en sus intentos de relevos favorables en el seno del ejército y de la marina. No procedió el juicio de amparo del general del ejército Víctor Silva Tuesta que pretendía involucrar y defenestrar al general Zegarra; tampoco resultó el intento de remoción del almirante Paniza por el desacato de una orden gubernamental en el asunto de la reparación de unos submarinos. No obstante, los apristas de las zonas militares lograron la mayoría de mandos, lo cual puede pesar en una decisión de fuerza den torno al proceso electoral. ${ }^{26}$

${ }^{26} \mathrm{Ibid}$. 
La actual campaña electoral de las fuerzas contendientes carece de apoyos estatales en materia de propaganda y se rige por la capacidad de financiamiento propia o concertada. Durante las recientes elecciones municipales, se estimó que el FREDEMO gastó 2959000 dólares, es decir $60 \%$ de los recursos invertidos en la campaña global. El Partido Aprista se aproximó al millón de dólares (18.9\%) mientras que las dos principales fuerzas de izquierda sólo bordearon el medio millón de dólares. ${ }^{27}$ Es probable que estos montos tiendan a triplicarse en el curso de la actual campaña electoral. En general, visto el ámbito latinoamericano y considerando el número de votantes potenciales, casi 10000000 , podemos decir que la actual campaña electoral es discreta. Queda claro que el peso decisivo de los mensajes electorales será evidentemente monopolizado por las derechas, el APRA incluido. El abismo propagandístico se hace mayor si tomamos como referencia los materiales técnicos, en su mayoría televisivos, de este marketing electoral tan favorable al FREDEMO.

El marketing electoral que se sitúa fundamentalmente como guerra de spots televisivos, tiene como rasgo característico el golpear ruda y reiteradamente sobre la credibilidad de sus oponentes. La Iglesia y las fuerzas armadas, han hechoun llamado a las agrupaciones políticas contendientes para modificar este estilo de confrontación, que en perspectiva puede revertirse en contra de todo el sistema político-electoral. Recientemente el tema de la propaganda sucia se ha evaluado mediante encuestas de opinión. ${ }^{28}$

${ }^{27}$ Sí, Lima, núm. 155, 12-19 de febrero de 1990.

${ }^{28}$ Oiga, Lima, núm. 469, 12 de febrero de 1990.
En lo que corresponde a las preferencias electorales, las encuestas de opinión se vienen levantando principalmente a partir de muestreos capitalinos, por lo que los mârgenes del sufragio real modificarán incluso los sondeos más confiables. Fuera de ello, hay que decir que las encuestas se han convertido en mecanismos de presión electoral utilizados preferentemente por el FREDEMO y en menor medida por el partido oficial. En lo que sí hay consenso es en el reconocimiento de que la candidatura presidencial de Mario Vargas Llosa, se ubica en su límite inferior por encima de $40 \%$ de los encuestados, seguido muy de lejos por sus contendientes. Según datos de una encuesta realizada por IMASEN en la ciudad de Lima a principios de febrero de este año, se registraron los siguientes resultados: Mario Vargas Llosa del FREDEMO $47.3 \%$, Alfonso Barrantes de la Izquierda Socialista $13.0 \%$, Henry Pease de Izquierda Unida 6.1\% y Luis Alva Castro del Partido Aprista con $5.1 \%$. Los seis candidatos restantes sumaron en total 1.3\%, no contrariado en lo general por los resultados de otras encuestas de opinión.

Finalmente, hemos de señalar que el funcionamiento del sistema político-electoral descansa en la puesta en marcha de la maquinaria coercitiva estatal a escala nacional, que combina los operativos de la guerra sicológica con los de vigilancia y protección de los candidatos y del propio proceso electoral, así como la realización de importantes acciones de rastrillaje antiterrorista, principalmente sobre las zonas marginales y céntricas de las más importantesciudades del país. En el campo, el empleo de helicópteros artillados y carros orugas le ha dado un nuevo sesgo a la guerra interna, forzando a las guerrillas a modificar de alguna manera los tiempos y modalidades de desplazamiento y ataque, con el fin de 
evitar estas ofensivas por aire, que técnicamente todavía no están en capacidad de repeler. Igualmente, las tareas de inteligencia militar se han redoblado asumiendo un carácter de alerta permanente.

Así las cosas, la cuestión de la defensa de los derechos humanos emergerá como el fantasma más real de la sociedad civil, prohijado por el maquillado sistema democrático que garantiza el relevo natural de los mandos políticos de este país andino.

\section{PERFILES POLITTICO-PROGRAMÁTICOS DE LAS FUERZAS ELECTORALES}

El 14 de abril de 1989, los líderes más connotados de las derechas posoligárquicas, Fernando Belaúnde Terry del Partido Acción Popular y Luis Bedoya Reyes del Partido Popular Cristiano, se sumaron al proyecto frentista promovido por el escritor Mario Vargas Llosa, líder del Movimiento Libertad; por último se adhirió a la misma causa el pequeño grupo empresarial denominado Solidaridad y Democracia que comanda Javier Silva Ruete.

El FREDEMO surge en la actual coyuntura como la respuesta política más articulada.de las derechas, frente a los agravios estatistas de Alan García y el desarrollo de las potenciales amenazas de las izquierdas como alternativas de poder. El detonantefue, sin lugar a dudas, el intento alanista de estatización de la banca privada con la finalidad de forzar al sector monopólico de la gran burguesía nativa a reactivar la esclerotizada economía peruana. El gobierno aprista se sentía traicionado por la elite empresarial exportadora -"los doce apóstoles"a la que había protegido con diversos y estimulantes incentivos tributarios, cambiarios, comerciales y aduaneros durante sus dos primeros años de gestión estatal, los cuales optaron por sacar divisas del país y abandonar el programa de reactivación económica nacional.

Los grandes empresarios nacionales, afectados sorpresiva y agresivamente en sus fueros financieros, reaccionaron políticamente concertando apoyos con los cuerpos empresariales y los partidos tradicionales: Acción Popular y Popular Cristiano, así como del novísimo Instituto Libertad y Democracia. En pocos días, los empresarios pasaron a librar la más importante ofensiva desestabilizadora del régimen aprista.

La lógica de los hechos colocó a este movimiento antigubernamental de las derechas como virtual alternativa de relevo, en el contexto de una deseada y posible aventura golpista. A pesar de ciertas vacilaciones, las fuerzas armadas prefirieron mantener cierta cautela profesional, propia de quienes tienen la conducción de una compleja guerra interna en la que iban gradualmente ganando posiciones los grupos de izquierda alzados en armas. Los mandos militares tenían claro que una "crisis en las alturas" de esta envergadura era peligrosa. El Partido Aprista mantiene una organización respetable y con experiencia en la lucha clandestina y en acciones paramilitares, además de ejercer cierta influencia en el seno de las propias fuerzas armadas y policiales. En este contextoun eventual golpe militar, con el fin de reprogramar nuevas elecciones, no era viable dada la presión guerrillera a la que sesumaría la propia del Partido Aprista. Así las cosas, los argumentos çastrenses fueron apaciguadores. La confrontación de proyectos políticos debería hacerse en el marco de una próxima contienda electoral, garantizada en su orden y legitimidad por las propias fuerzas armadas. Había también que respetar el cumplimiento del 
periodo gubernamental de Alan García, sin dejar de presionar con más fuerza sobre el curso de la política gubernamental.

En este contexto y perspectiva el Instituto Libertad y Democracia (ILD) jugó un papel decisivo en la tarea de concertación de las fuerzas de filiación conservadora. Fundado en 1980 por destacados líderes de la derecha peruana, muy vinculados a organismos estadunidenses solventados por el Departamento de Estado, como el ex parlamentario y cronista de la embajada norteamericana en Lima, Enrique Chirinos Soto y Andrés Towsend Ezcurra, ex aprista y ex director de un instituto de capacitación política en Costa Rica. Perolas principales cabezas del ILD eran Hernando de Soto Polar, ideólogo empresarial y autor del Otro sendero, y el conocido novelista Mario Vargas Llosa.

Existen algunas afinidades significativas entre las propuestas del ILD y los lineamientos fijados por el proyecto Democracia promovido por el Departamento de Estado norteamericano bajo la administración Reagan, pero sería exagerado suponer a partir de ello que el ILD es un organismo apoyado por la Casa Blanca. Las afinidades de las derechas internacionales son análogas a las que existen entre las izquierdas, sin que por ellohaya que identificarmaniqueamente la presencia enmascarada de una potencia extranjera en todos los casos.

En el seno del ILD se formó el Movimiento Libertad y Democracia, dirigido por Mario Vargas Llosa y que jugó un papel aglutinante de los sectores más conservadores del país mediante el Frente Democrático (FREDEMO).

Hay que precisar que en tanto político, Vargas Llosa destaca como un gran antagonista y muy eventualmente como un concertador. El curso de los compromi- sos políticos de esta nueva agrupación suscitó un distanciamiento progresivo entre el novelista y el director del ILD, Hernando de Soto. Este no fue el único disenso; la crisis del FREDEMO a mediados de 1989, fue suscitada por el protagonismo absorbente de Vargas Llosa. Si bien el impasse se resolvió a favor del temperamental autor de La guerra del fin del mundo, estos antecedentes, tan cercanos en la coyuntura, auguran futuros problemas. Y es que una conducción política estable demanda menos desbordes emocionales en los desacuerdos y mayor flexibilidad política para forjar una nueva concertación en sus filas, así como para establecer alianzas o compromisos con fuerzas externas y políticas disímiles.

Lo que llama la atención del FREDEMO es el excesivo énfasis en la búsqueda de una afirmación más ideológica que programática, la cual a parece en una especie de adhesión mística a su fantasmagórica utopía liberal: "de devolverle al Perú, en Libertad, su condición histórica de país a la vanguardia de su tiempo gracias al celo creador y a la diligencia de sus mujeres y sus hombres [...] devolverle a nuestro pueblo la fe en la democracia, a nuestros jóvenes la confianza en el futuro y arraigar en nuestro suelo, para siempre, la cultura del éxito y de la libertad, que es también la del bienestar y la eficiencia". ${ }^{29}$

Durante el discurso de la campaña electoral, Mario Vargas LLosa ha traducido su utopía finalista al lenguaje más terrenal de los potenciales electores, ofreciéndoles como él mismo dice, "capitalismo", pero capitalismo paradisiaco que hay que refundar en el suelo de este país

\footnotetext{
${ }^{29}$ Acta de constitución del Frente Democrático, 14 de abril de 1989.
} 
andino, porque su misión histórica fue usurpada y distorsionada por el vil "mercantilismo". Además afirma Vargas Llosa, el capitalismo auténtico fue satanizado por las ideologías totalitarias y extremistas de las izquierdas.

El mercantilismo aparece así, en el vocabulario fredemista, como una tergiversación autoritaria, estatista y discriminatoria del capitalismo. La resemantización democrática del capitalismo a partir del eslabonamiento doctrinario de la libertad, la propiedad y el bienestar para todos, aparece como un mensaje para ese contingente decisivo del proceso electoral conformado por las agobiadas y pauperizadas capas medias urbanas, hasta hace poco clientela entusiasta de los efimeros éxitos del populismo tardio del presidente Alan Garcia y de Alfonso Barrantes Lingán, ex alcalde de Lima.

La utopía fredemista tiene en la propaganda electoral muchas posibilidades de traducción política. He aquí una de las claves de su relativo éxito. iQué distinto lenguaje del "escribidor", al usado con tono restaurador por los líderes de Acción Popular y del Popular Cristiano! La religiosidad política fredemista no se agota en la visión edénical del futuro ni en la práctica ritual de exorcizar a sus potenciales adeptos, frente a las tentaciones demoniacas de las izquierdas. La mística fredemista se articula con un enjuiciamiento apocalíptico del presente político y de las prácticas de poder de los populismos y las izquierdas dentro y fuera de Perú. En su afán de purificar al nuevo Perú que se gestará bajo su probable gobierno, ha ofrecido no sólo dirigir la extirpación de todo terrorismo sino romper además con las malas relaciones diplomáticas, refiriéndose muy concretamente a Corea del Norte y Cuba.

Finalmente, Vargas Llosa mediatiza su discurso a fin de que sus electores no caigan en la desilusión en caso de que él sea presidente, y los prepara para el ejercicio de un apostoladoredentor. Por ello, Vargas Llosa no olvida reiterar en cada una de sus prédicas electorales que el pueblo peruano "ha sufrido mucho, pero está dispuesto a sufrir un poco más si podemos mostrarle que ello no será inútil". ${ }^{30}$

Una somera revisión de las "Bases para el Plan de Gobierno del Frente Democrático (1990-1995)" revela la amalgama entre las categorías ideológicas y los elementos de diagnóstico o decarácter programático que subrayan que el aspecto más grave de la crisis del país se ubica en el plano social debido a la coexistencia y relación entre pobreza, terrorismo y narcotráfico.

La actual crisis económica, social y política que ha llevado al país al "borde del abismo" la explica el FREDEMO a partir de seis factores causales: la función interventora del Estado que ha "pervertidolos cimientos de la economía nacional"; "el deterioro de valores fundamentales que, afectando a la célula básica de la sociedad que es la familia, ha resentido la conciencia de identidad y la solidaridad entre los peruanos"; la corrupción social y administrativa derivadas de la "falta de respeto por la Constitución y sus principios"; la existencia de un "sistema económico incapaz de atender las múltiples carencias de la población" y finalmente "la conducta protagónica del presidente de la república y el copamiento de poder por parte de él y del partido del gobierno". ${ }^{31}$

La propuesta gubernamental del FREDEMO, a diferencia de las plataformas

${ }^{30}$ Excélsior, 6 de noviembre de 1989.

${ }^{31}$ Bases para el Plan de Gobiemo del Frente Democrático (1990-1995). 


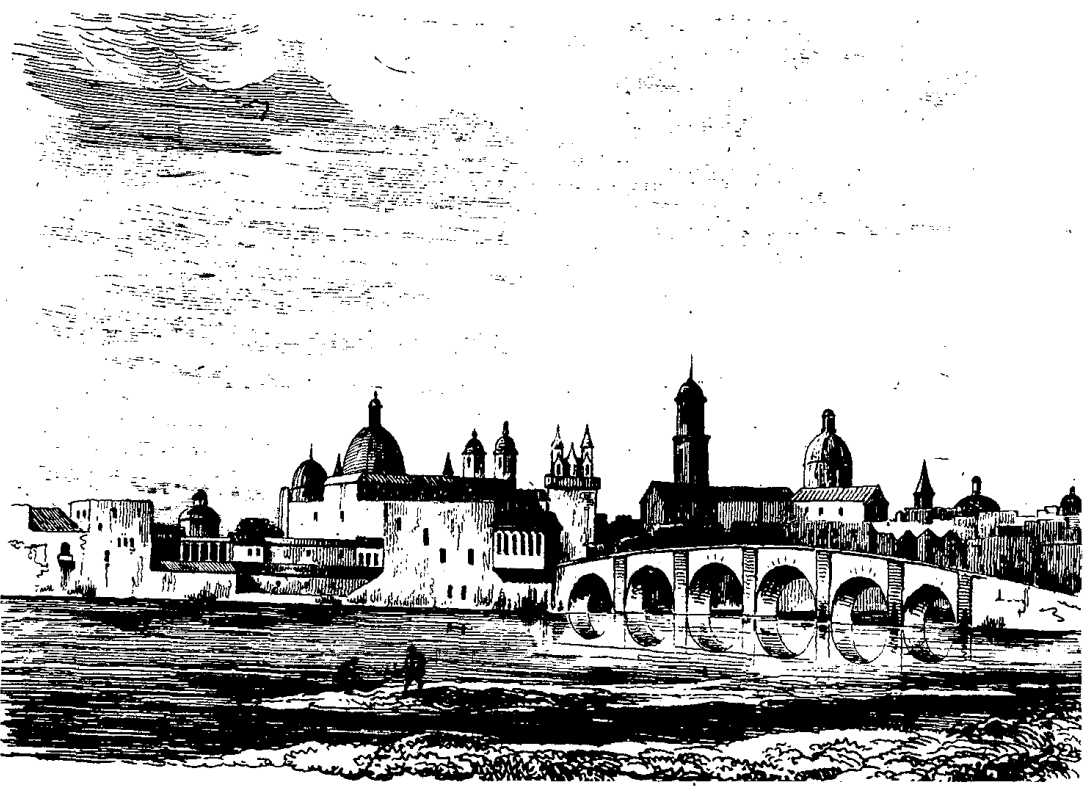

electorales del APRA y de las izquierdas en las que subyace una matriz conceptual legada por las corrientes teóricas alternativas de las ciencias sociales, la signa principalmente su mosaico doctrinario liberal-conservador. Vano sería por ello comentar la confusión entre las manifestaciones sintomáticas de la crisis nacional y las presuntas fuerzas o factores causales, si el objetivo es penetrar en el mismo corazón y cerebro de sus dogmas neoliberales. Los discutibles presupuestos cientificistas formulados por el ideólogo Hernando de Soto en su best-seller, El otro sendero, acerca de los antagonismos entre capitalismo y mercantilismo, economía informal y estado burocrático, economía de mercado y Estado empresario, así como entre democracia y libertad por un lado y Estado interventor por el otro, aparecen programática e ideológicamente, implícita e explícitamente en el primerdocumento político del FREDEMO.

Los objetivos programáticos que se desprenden de este peculiar diagnóstico fredemista implican en lo económico un plan de choque que tiene como objetivo bajar a $10 \%$ la actual tasa inflacionaria, estimada en $2775 \%$. La reducción de los gastos fiscales, suprimiendo los subsidios a los productos alimenticios y combustibles, cuyo volumen creciente de importación encarece el costo de la vida, generará más descontento popular. La privatización en general de las empresas estatales apunta a golpear la estabilidad laboral de importantes contingentes de obreros y empleados, así como de sus respectivos grupos sindicales, en la misma dirección que la anunciada reducción burocrática en medio millón de empleos. Ante la evidente reacción negativa de los trabajadores a causa de estas duras 
medidas anunciadas por Vargas Llosa que pueden estancarsu marcha electoral hacia el ansiado y difícil $51 \%$ de los votos válidos, el líder fredemista se ha visto obligado a matizar su propuesta agregando la fórmula mágica del capitalismo popular.

Las izquierdas y el aprismo sostienen que un programa de esta naturaleza originaría un colapso económico que producirá la recesión y el agravamiento de la violencia social y política en el país, lo cual a su vez sería capitalizado por el MRTA Y SL.

En lo que respecta a la situación de guerra interna, el FREDEMO postula un etéreo programa de pacificación nacional que implica elevar el curso de la guerra a su plano más general. ¿Cómo deben entenderse los objetivos de lograr "la participación resuelta de la sociedad" contra la violencia en todas sus formas y la "movilización de todo el país" en las tareas de pacificación nacional?

El FREDEMO habla de un "Plan nacional de pacificación" que involucre a todas las instituciones sociales. El papel rector de este plan lo llevarán a cabo las fuerzas armadas, por lo que habrá que brindarles el "apoyo a las fuerzas del orden en una estrategia subversiva de alta especialización profesional". El antiestatismo de FREDEMO de pronto se esfumó por completo. La concentración del poder y autoridad en manos de las fuerzas armadas y del ejecutivo para librar la guerra final, no parece entrar en contradicción con su pretendido ideario liberal, aun cuando tenga que barrer con algunos derechos elementales como el derecho a la vida.

En este marco, la visión dicotómica del Estado queda legitimada por la función democrâtica de a plastar a las guerrillas: "La violencia, incubada durante la dictadura (sic), se expresa hoy en movimientos ligados, desde antiguo, al mar- xismo-leninismo, que intentan destruir el sistema democrático y sustituirlo por un proyecto dogmático y totalitario." 32 En una reciente declaración a la prensa internacional Vargas Llosa sostuvo, refiriéndose a lasizquierdas, quesus líderes intelectuales se han prohijado en las universidades estatales, a las que calificó de "nidos de extremistas marxistas-leninistas", repitiendo una apreciación interesada de la Sociedad para las Américas que dirigen David Rockefeller y Henry Kissinger.

Fuera del FREDEMO debemos considerar que el segundo bloque electoral alternativo, es más una aspiración que una realidad. Nos referimos al Partido Aprista dirigido por Luis Alva Castro y la Izquierda Socialista de Alfonso Barrantes Lingán, que apuntan en perspectiva a una probable segunda ronda electoral que les serviría de eje.

Luis Alva Castro es un candidato agobiado por el descalabro de la administración de Alan García. Los esfuerzos sostenidos durante el quinquenio que ahora concluye, con el fin de guardar las distancias políticas con su controvertido presidente, no le han impedido al APRA sumirse en el ranking más bajo de los sondeos electorales. La actual plataforma electoral del partido Aprista la reseña con habilidad el sociólogo Víctor López, responsable de la Comisión de Plan de Gobierno. Para López, "el principal problema que confronta actualmente el país es el de la violencia subversiva y terrorista", en segundo lugar, "la escasa experiencia democrática y el insuficiente desarrollo institucional". Finalmente, "la crisis económica y el problema social", redondean las principales aristas de la problemática nacional.

${ }^{32}$ Ibid. 
Frente a estos males el aprismo propone una estrategia integral de lucha contra la subversión y el terrorismo basada en un "acuerdo nacional de pacificación"; en el plano político sugiere el otorgamiento de un papel más dinámico a la presidencia en las tareas y acciones de concertación entre ministerios, así como la instalación de una cámara única de representantes y la implantación de diversas medidas desburocratizadoras. Habría que agregar un programa de "reformas estructurales" y otro de estabilización económica. ${ }^{33}$

Por su lado, Alfonso Barrantes Lingán, otrora líder de las izquierdas, representa a la facción más reformista, que gradualmente se ha vuelto satélite por la acción paralizante del partido Aprista bajo la gestión de Alan García.

Según Francisco Guerra García, director del Plan de Gobierno de Izquierda Socialista, su agrupación parte del reconocimiento de quela "gravísima situación que atraviesa el Perú es la expresión de una crisis global" a la que hay que oponer igualmente un proyecto global para "reestructurar el Estado, conjurar la crisis económica e iniciar la transformación del aparato productivo y, al mismo tiempo, combatir la violencia, el narcotráfico y todas las formas de descomposición social que amenazan la vida misma del país. ${ }^{n+4}$

El enfoque barrantista, que ve los problemas de Perú de modo global, se aproxima a la valoración aprista de la coyuntura. Sin embargo, se distancian en los énfasis otorgados a la economía, a la violencia politica y al narcotráfico. En cuanto a las medidas a tomar, coinciden en la necesidad de concertar un acuerdo multipartidario. Francisco Guerra sostiene

${ }^{33}$ Caretas, núm. 1090, Lima, 8 de enero de 1990. * Ibid. como tareas prioritarias, un programa de estabilización y crecimiento económico de implicación corporativa y por tanto muy próximo a la alternativa aprista; un proyecto de reestructuración del Estado en favor de los gobiemos regionales y locales; renegociación de la deuda y nuevos créditos a partir de las bases económicas concertadas; y en el delicado punto dela contrainsurgencia, menciona que de llegar al poder se ejecutará "una estrategia de pacificación que, conducida por un comando único, actuará en los dominios económico, psicosocial y militar, movilizando al conjunto de las institucionesy organizaciones sociales del país". ${ }^{35}$

La principal dificultad para la conformación de este bloque electoral del APRA y las izquierdas, pasa por la distinta y polar caracterización del Comando Rodrigo Franco. El APRA ha asumido una actitud de abierto encubrimiento de sus acciones terroristas y de los vínculos probados que mantiene con algunos jerarcas de su partido.

Por su lado, la agrupación Izquierda Unida que postula a Henry Pease, ha marcado sus diferencias y distancias políticas con el barrantismo, tanto en lo que concierne a la tipificación del aprismo como en lo que compete a las principales reivindicaciones y tareas gubernamentales.

Izquierda Unida centra los problemas del país en el reconocimiento de la existencia de la "miseria y falta de oportunidades de progreso económico"; "la ausencia de un Estado democrático y nacional" y "la violencia político-militar y la inseguridad ciudadana". En lo que respecta a este último y polémico punto, la propuesta correctiva se apoya en la "generalización de la autodefensa de

${ }^{35} \mathrm{Ibid}$. 
masas. La tarea organizativa de la población en todo el territorio de la república será la fundamental, pero vendrá acompañada de otras iniciativas ideológicas, políticas y militares."36

La ambigüedad de estas iniciativas que eluden implícitamente a las fuerzas armadas, revela la coexistencia de dos tendencias, una autonomista de clase y otra ligada al barrantismo, es decir, de subordinación a la doctrina de seguridad nacional y sus cuerpos especializados, que no violenta indiscriminadamentelos derechos humanos. Esta versión fue rebautizada por Armando Villanueva del Campo, líder del APRA, como "Doctrina deSeguridadColectiva". Esta ambigüedad del proyecto de pacificación de Izquierda Unida abre la posibilidad de un realineamiento político de las izquierdas, ante una eventual segunda ronda electoral en favor del APRA.

En general, el panorama de las izquierdas electorales en la actual coyuntura política, sevenítidamente disminuido. El acoso de que son objeto por parte de las derechas y delasinstituciones castrenses, en el sentido de diferenciarse cada vez más de las fuerzas de izquierda en armas, ha limitado grandemente su acción política, además de haber perdido base social en el campo popular.

Visto en su conjunto, el panorama electoral peruano revela el peso decisivo que han adquirido las fuerzas armadas y que no responde únicamente a la situación de guerra interna. Después de la segunda posguerra las fuerzas armadas han ejercido de manera directa el poder durante 21 años, y han fungido en los dos últimos quinquenios gubernamentales como entidad fiscalizadora e interventora de la vida política nacional. Nada parece indicar que en esta década

${ }^{36} \mathrm{Ibid}$.

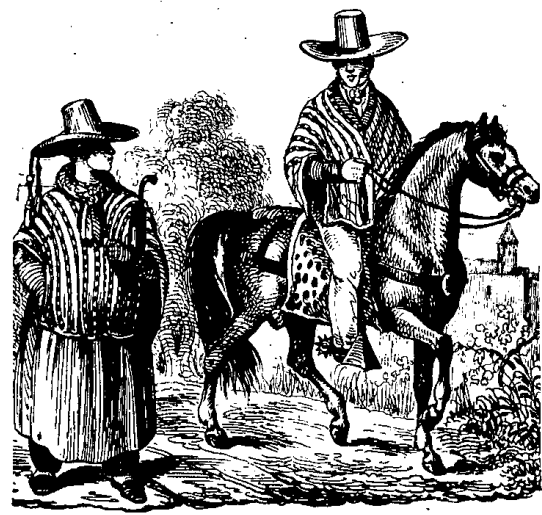

los militares peruanos abandonarán los espacios políticos ya conquistados, muy al contrario, las diversas propuestas de pacificación les confieren legitimidad jurídico-política y base social.

En cuanto al legado económico que heredará el nuevo gobierno, hay consenso en señalar que es poco menos que territorio minado; agotadas casi las reservas monetarias, vencidos los plazos del servicio de la deuda externa, además de las marcadas tendencias recesivas de la economía, el nuevo gobierno necesitará algo más que créditos frescos, promesas de inversión y respaldo militar.

\section{POST SCRIPTUM}

Durante la primera quincena de marzo de 1990 , periodo en que hicimos entrega de este articulo, ni las fuentes hemerográficas ni los sondeos electorales realizados por las principales empresas encuestadoras (POP, DATUM, APOYO, CPI, APEIM y Analistas y Consultores), registraban fuera del rubro de "otros candidatos" al aspirante presidencial Alberto Fujimori y su naciente organización política: Cambio 90, asig- 
nándole a todos ellos un magro promedio que fluctuaba entre 2 y $3.8 \%$. Ningún analista pudo prever en ese entonces el vertiginoso ascenso político de este hijo de inmigrantes japoneses y ex presidente de la Asamblea Nacional de Rectores delas UniversidadesPeruanas, a partir de una modesta pero tesonera campaña electoral bajo el lema de "Honestidad, trabajo y tecnología" y una propuesta programática que gracias a su ambigüedad logró situarse en un punto equidistante de los extravios demagógicos del aprismo y de las alucinaciones políticas de la derecha fredemista.

Los resultados de la primera ronda electoral fueron y siguen siendo sorprendentes: Mario Vargas Llosa ganó por escaso margen porcentual al fulgurante Alberto Fujimori, quien sepultó las aspiraciones frentistas del aprismo y de las izquierdas de pasar a la segunda ronda electoral, forzándolas a un embarazoso realineamiento político que tiene como única brújula la oposición al FREDEMO.

Sin lugar a dudas, el punto de viraje electoral se hizo visible en la segunda quincena de marzo, a escasas tres semanas de los comicios generales. En el caso peruano, los sondeos de opinión registraron este brusco giro político del electorado peruano en favor de Fujimori. Con este registro tardío, pero oportuno a fin de cuentas, las empresas encuestadoras tuvieron menos errores que en las nicaragüenses y no perdieron legitimidad técnica y política.

Queda por descifrar esta lógica de la recomposición de las fuerzas electorales más allá de las eternas "razones post factum" de nuestros analistas electorales: para explicar el fenómeno Fujimori: la sobresaturación de la propaganda fredemista, el maquiavelismo de Alan García, el trabajo de hormiga de los pastores evangélicos, su imagen mítica de hijo del sol naciente o andino, etc. Loúnico indiscutible es que el viraje político cubre un breve lapso que va de la segunda quincena de marzo a fines de abril, en el cual Fujimori no sólo pasó a ocupar el segundo lugar en la primera ronda electoral, sino que avanzó hasta volverse el aspirante de mayor fuerza para la segunda vuelta. Es probable que la constante referencia a frenar la guerra del Estado y de la DEA contra las guerrillas y el narcotráfico, así como una mesurada postura frente a la privatización de las empresas públicas, hayan pesado más, o por lo menos tanto como sus otros atributos carismáticos y simbólicos, en un pueblo agobiado por la crisis económica, la guerra interna y la falta de credibilidad política en los ya gastados y añejos liderazgos políticos agazapados a la sombra de Mario Vargas Llosa.

Difícil perspectiva preelectoral en la que las presiones institucionales de las fuerzas armadas, de las iglesias y de los cuerpos empresariales, así como las estrategias de confrontación simbóli$\mathrm{ca}$, pueden reafirmar estas tendencias del electorado peruano, pero también propiciar una vez más, una variación significativa de la actual correlación de fuerzas.

Lo mássorprendente del proceso electoral en curso es que los alineamientos religiosos y etnoclasistas prevalecen sobre la capacidad de convocatoria de los tradicionales agrupamientos políticos de las derechas y de las izquierdas, habiendo incluso abatido de manera sensible el porcentaje de votos blancos y viciados. Además de los católicos y evangélicos, del lunar blanco y las manchas de color, el momento político no deja pasar por alto las banderas "salvacionistas" de las guerrillas del MRTA y de Sendero Luminoso, que en su conjunto signan los diversos rostros de la política andina. 